\title{
Parametric study of dry coating process of electrode particle with model material of sulfide solid electrolytes for all-solid-state battery
}

\author{
Takashi KAWAGUCHI, Hideya NAKAMURA*, and Satoru WATANO \\ Department of Chemical Engineering, Osaka Prefecture University \\ 1-1 Gakuen-cho, Naka-ku, Sakai, Osaka 599-8531, Japan \\ *Corresponding author. Tel.: +81 72254 9451, fax: +81 722549217 . \\ E-mail address: hnakamura@chemeng.osakafu-u.ac.jp (H. NAKAMURA)
}

\begin{abstract}
We have reported that a dry coating is a very promising process to produce a suitable composite particle for all-solid-state lithium-ion secondary batteries. We here present a parametric study of this dry coating process for further optimization and improvement. In the dry coating process, electrode particles were coated with solid electrolyte (SE) particles. $\mathrm{LiNi}_{1 / 3} \mathrm{Co}_{1 / 3} \mathrm{Mn}_{1 / 3} \mathrm{O}_{2}(\mathrm{NCM})$ was used as a host particle, while sodium sulfate $\left(\mathrm{Na}_{2} \mathrm{SO}_{4}\right)$ was selected as a model material of sulfide SEs and used as a guest particle. A dry impact-blending process known as "Hybridizer" was used. Effects of critical process parameters including tip speed of rotor, processing time, and initial weight fraction of host and guest particles were investigated. Under insufficient impact force NCM particles were not fully covered with $\mathrm{Na}_{2} \mathrm{SO}_{4}$ particles, while under a sufficient impact force the discrete coating of $\mathrm{Na}_{2} \mathrm{SO}_{4}$ particles on the surface of $\mathrm{NCM}$ particles were observed. With an increase in the mechanical input energy per unit mass of $\mathrm{Na}_{2} \mathrm{SO}_{4}$, plastic deformation and coalescence of $\mathrm{Na}_{2} \mathrm{SO}_{4}$ particles were promoted, resulting in the continuous coating. With further increase in the mechanical input energy, breakage of the NCM particles was caused. The continuous coating exhibited a great advantage over the discrete coating for formation of the solid-solid interfacial contacts between $\mathrm{NCM}$ and $\mathrm{Na}_{2} \mathrm{SO}_{4}$ in the compressed pellet. Finally, the optimal processing conditions, where NCM particles are able to be coated by the continuous layer of much less amount of $\mathrm{Na}_{2} \mathrm{SO}_{4}(=10 \mathrm{wt} \%)$ without breakage of NCM particles, were determined.
\end{abstract}

Keywords: dry coating; all-solid-state battery; composite particle 


\section{Introduction}

A new next generation secondary battery for large-scale power storage devices has been strongly required for hybrid electric vehicles (HEVs) and electric vehicles (EVs), renewable energy productions, smart grid applications, and so on [1,2]. Lithium-ion secondary batteries (LIBs), which are widely used in portable electronic devices, are considered as a potential candidate for the large-scale secondary battery. However, LIBs have a serious safety concern for application to the large-scale battery, because the organic liquid electrolytes used in the current LIBs are flammable. As a promising candidate of next generation secondary battery, all-solid-state lithium-ion secondary batteries (ASS-LIBs) have attracted much attention [3-5]. In the ASS-LIBs, inorganic solid electrolytes (SEs) are used instead of the organic liquid electrolytes. SEs are non-flammable materials and stable under higher voltage and broad temperature range. Due to these features, the ASS-LIBs are highly expected to be a next generation secondary battery with both high safety and high energy density.

For development of the ASS-LIBs, there are two major issues: (1) synthesis of new inorganic materials for SEs, and (2) development of processing technologies to produce composite electrodes. The lithium-ion conductivity of typical SEs was lower than that of organic liquid electrolytes [4]. To date, material scientists have synthesized new inorganic materials with higher lithium-ion conductivity. Among the candidate materials, sulfide SEs have been extensively investigated for the ASS-LIBs [3, 4, 6-10]. Recently, new sulfide SE which exhibits equivalent lithium-ion conductivity to organic liquid electrolytes has been synthesized [10]. However, high performance of the ASS-LIBs cannot be accomplished only by synthesizing new materials for SEs. In the ASS-LIBs, transfer of lithium ions during charging and discharging only occurs at the interfacial contact surface between an electrode particle and SE. This requires well-designed composite particles and electrodes in which solid-solid interfacial contacts between electrode particles and SEs for the lithium-ion conduction pathway is formed [3,4]. Moreover, breakage of the electrode particles, that can lead to negative impact on the battery performance of the ASS-LIBs, $\underline{\text { should be avoided. Therefore, development of processing technologies to construct the solid-solid }}$ interfacial contacts in the composite particles and electrodes without breakage of the electrode particles is also important issue.

Many studies on the processing technologies to produce the ideal composite particles and electrodes have been reported. Some simple powder mixing techniques such as the use of smaller size of $\underline{\text { SEs }[11] \text { and wet mixing of electrode particles and SE particles [12] have been studied. These studies }}$ indicate that performance of the ASS-LIBs can be improved even by these simple powder handling 
techniques. A planetary ball milling $[13,14]$ has often been used for mixing of electrode particles and SE particles. To achieve better composite particles, agglomerates of fine electrode and SE particles should be disintegrated sufficiently without breakage of the electrode particles. However, no one has succeeded in such an ideal mixing, suggesting that the planetary ball milling is less suitable for the processing technology to produce the composite particles and electrodes. To produce better composite particles and electrodes, it is ideal that the primary electrode particles are individually coated with SEs without breakage of the electrode particles. Such an ideal coating has been examined by means of a pulsed laser deposition (PLD) $[15,16]$. In this technology, SE layer can be deposited on surface of the electrode particles, resulting in coating of primary electrode particles with the SE. The authors demonstrated a significant improvement in the battery performance using the coated particles. However, the PLD has disadvantages of low throughput and much expensive running cost due to significant low formation rate of the coating layer. Thus, the PLD is very expensive and far from practical use in an industrial process [4]. Apart from the powder handling equipment, hot pressing at temperatures above the glass transition temperatures of SEs [17] have also been attempted. However, the heating treatment can reduce the battery performance.

In our previous study [18], we proposed to apply a dry coating process and reported that individual primary electrode particles (host particles) are able to be successfully coated with a model material of sulfide SEs (guest particles). In a compacted pellet (i.e., mimic of composite electrode) prepared from the coated particles, the solid-solid interfacial contacts between electrode particles and the model material of SEs are well formed, suggesting that the dry coating process is very effective to produce composite particles and electrodes with the ideal structure for the ASS-LIBs. However, effects of many processing conditions on the coated particles have not been investigated, and there is much room for further improvement and optimization of the process.

We here present a parametric study of the dry coating process. $\mathrm{LiNi}_{1 / 3} \mathrm{Co}_{1 / 3} \mathrm{Mn}_{1 / 3} \mathrm{O}_{2}(\mathrm{NCM})$ which is a typical cathode active material was used as a host particle. Sodium sulfate $\left(\mathrm{Na}_{2} \mathrm{SO}_{4}\right)$ was selected as a model material of sulfide solid electrolytes and used as a guest particle. The dry impact-blending device was used as a dry coating device. Effects of critical process parameters including tip speed of rotor, processing time, and initial weight fraction of host and guest particles were systematically investigated. Through this investigation, mechanism of the dry coating in this study was discussed. Finally, the optimal processing conditions were determined. 


\section{Experimental}

\subsection{Equipment}

A dry impact-blending process (Hybridizer NHS-0, Nara Machinery Co., Ltd.) was used as a dry coating device (Fig. 1). This devise mainly consists of chamber (inside diameter of $125 \mathrm{~mm}$, depth of 49 $\mathrm{mm}$, and effective volume of $470 \times 10^{3} \mathrm{~mm}^{3}$ ), rotor with six blades (diameter of $118 \mathrm{~mm}$ ), and circulation pipe. The dry coating was conducted as follows. A pre-mixed powder mixture of host and guest particles was fed into the chamber. The rotor was then rotated and the particles circulate in the device. During the circulation, the particles are subjected to high impact forces due to particle-to-wall and particle-to-particle collisions. As a result, agglomerates of the particles are disintegrated and surface of the host particles are covered with guest particles, resulting in the dry coating. After a predetermined processing time, the discharge valve is opened, and coated particles are collected.

\subsection{Powder samples}

$\mathrm{LiNi}_{1 / 3} \mathrm{Co}_{1 / 3} \mathrm{Mn}_{1 / 3} \mathrm{O}_{2}$ (NCM) (NCM-03, Toda Kogyo Corp.) and sodium sulfate $\left(\mathrm{Na}_{2} \mathrm{SO}_{4}\right)$ (JIS special grade, Wako Pure Chemical Industries, Ltd.) were used as powder samples. Fig. 2 shows the volume based particle size distributions and SEM images of the powder samples. NCM is a typical positive-electrode active material for LIBs. Volume based median diameter of the NCM was $5.4 \mu \mathrm{m}$. $\mathrm{NCM}$ is relatively rigid, brittle, and electrically conductive material, as compared to $\mathrm{Na}_{2} \mathrm{SO}_{4}$. $\mathrm{NCM}$ was used as a host particle in the dry coating. $\mathrm{Na}_{2} \mathrm{SO}_{4}$ was selected as a model material of sulfide SEs [18], because sufficient amount of sulfide SEs to conduct our experiments is commercially unavailable. For selecting a model material of sulfide SEs, we considered that following properties are important: (i) nature of the room-temperature pressure sintering; (ii) mechanical properties such as stiffness and elastoplasticity. It has been reported that sulfide SEs exhibit the unique densification property so called "room-temperature pressure sintering [16]": when powder of a sulfide SE is compressed, the sulfide SE particles are able to be easily deformed and coalesced even at a room temperature. This results in a compressed pellet in which $\underline{\text { the original SE particles are continuously coalesced, and void spaces and particle boundaries are almost }}$ vanished. In this study, the model material of sulfide SEs was selected from a few inorganic materials which exhibit the room-temperature pressure sintering. We then measured the stiffness and elastoplasticity of the candidate materials by means of an indentation test [18]. As a result, $\mathrm{Na}_{2} \underline{\mathrm{SO}}_{4} \underline{\text { showed }}_{\text {she }}$ room-temperature pressure sintering as well as similar stiffness and elastoplasticity with a sulfide SE [18]. $\underline{\text { Consequently, } \mathrm{Na}_{2}} \underline{\mathrm{SO}}_{4}$ was selected and used in this study as a model material of sulfide $\mathrm{SEs}_{2} \mathrm{Na}_{2} \mathrm{SO}_{4}$ is 
relatively soft, ductile, and non-conductive material, as compared to $\mathrm{NCM}$. $\mathrm{Na}_{2} \mathrm{SO}_{4}$ was used as a guest particle of the dry coating. The as-received powder of $\mathrm{Na}_{2} \mathrm{SO}_{4}$ was preliminarily milled by a multi-ring-type wet grinding system (MICROS-0, Nara Machinery Co., Ltd.). Volume based median diameter of the $\mathrm{Na}_{2} \mathrm{SO}_{4}$ after the wet milling was $0.95 \mu \mathrm{m}$.

\subsection{Experimental procedure and conditions}

$\mathrm{NCM}$ and $\mathrm{Na}_{2} \mathrm{SO} 4$ were pre-mixed by mortar-and-pestle mixing for $30 \mathrm{~min}$. This pre-mixture was then processed by the dry impact-blending device. Table 1 shows processing conditions of the dry coating. Effects of the tip speed of rotor, processing time, and initial weight fraction of $\mathrm{NCM}$ and $\mathrm{Na}_{2} \mathrm{SO}_{4}$ particles were investigated. Total weight of $\mathrm{NCM}$ and $\mathrm{Na}_{2} \mathrm{SO}_{4}$ were $10.0 \mathrm{~g}$ in all experimental runs. The dry coating experiment was conducted one time at each Run. No., except for the Run No. 11. We confirmed that there is reproducibility in the dry coating experiment and there is no need to consider the batch deviation.

\subsection{Characterization}

FESEM equipped with an EDX spectroscopy (SU8200, Hitachi, Ltd.) was used to observe surface morphology of particles. A net weight fraction of $\mathrm{NCM}$ and $\mathrm{Na}_{2} \mathrm{SO}_{4}$ in the dry coated particles was measured by an ICP-AES (SPS7800, Seiko Instruments Inc.). To evaluate the breakage of NCM particles after the dry coating, $\mathrm{Na}_{2} \mathrm{SO}_{4}$ of the coated particles was washed out in water and size distribution of the NCM particles after the washing out was measured using a laser diffraction particle size analyzer (SALD-2100, Shimazu Corp.). Compressed pellets, which mimic the composite electrode, were prepared from the dry coated particles. The coated particles of $0.50 \mathrm{~g}$ was initially charged into a die (10 mm of inner diameter) and compressed using a hand press at a compression pressure of $360 \mathrm{MPa}$. Inner wall of the die is made of non-conductive polyacetal resin, while the upper and lower punches were made of conductive stainless steel. A DC electrical resistivity of the pellet inside the die in vertical direction was measured using an electrometer (Model 6514, KEITHLEY). Increase in electrical resistivity normalized by the net weight fraction of $\mathrm{Na}_{2} \mathrm{SO}_{4}\left(R_{\text {inc }}\right)$ [18] was then calculated by:

$$
R_{\mathrm{inc}}=\frac{R_{\mathrm{DC}}-R_{\mathrm{NCM}}}{x_{\mathrm{Na}_{2} \mathrm{SO}_{4}}}
$$


where $R_{\mathrm{DC}}$ and $R_{\mathrm{NCM}}$ are electrical resistivities of compressed pellets prepared from dry coated particles and prepared from NCM particles, respectively. $x_{\mathrm{Na} 2 \mathrm{SO} 4}$ is the net weight fraction of $\mathrm{Na}_{2} \mathrm{SO}_{4}$. States of the NCM-Na $\mathrm{SO}_{4}$ interfacial contacts were evaluated using $R_{\text {inc }}$ : if $\mathrm{NCM}$ is well coated with $\mathrm{Na}_{2} \mathrm{SO}_{4}$ and the NCM-Na $\mathrm{SO}_{4}$ interfacial contacts are well formed, $R_{\text {inc }}$ becomes higher due to non-conductivity of $\mathrm{Na}_{2} \mathrm{SO}_{4}$; if the NCM-Na $\mathrm{SO}_{4}$ interfacial contacts are not well formed, networks of conductive NCM particles are formed in the pellet, thus resulting in lower $R_{\text {inc }}$. The $\mathrm{NCM}-\mathrm{Na}_{2} \mathrm{SO}_{4}$ interfacial contacts in the pellets were also observed through FESEM observation of cross-section of the pellets. Cross-sections of the pellets were prepared using an argon ion beam cross-section polisher (IM4000, Hitachi, Ltd.).

\section{Results and discussion}

\subsection{Effect of tip speed of rotor}

Fig. 3a shows FESEM and EDX images of dry coated particles prepared at different tip speeds of rotor (Run No. 1, 2, and 3 in Table 1). Elemental mapping images of manganese and sulfur show the presence of NCM (host particle) and $\mathrm{Na}_{2} \mathrm{SO}_{4}$ (guest particle), respectively. At each tip speed, manganese of NCM and sulfur of $\mathrm{Na}_{2} \underline{\mathrm{SO}}_{4}$ were detected at the same location, confirming that NCM particles were covered with $\mathrm{Na}_{2} \underline{\mathrm{SO}}_{4}=$ At $50 \mathrm{~m} / \mathrm{s}$ of tip speed, surface morphology of the pristine NCM (rectangular-shaped grains) was still observed, although NCM particles were partially covered with $\mathrm{Na}_{2} \mathrm{SO}_{4}$ particles. At $80 \mathrm{~m} / \mathrm{s}$, the surface morphology of the pristine $\mathrm{NCM}$ was no longer observed and NCM particles were almost fully covered with $\mathrm{Na}_{2} \mathrm{SO}_{4}$. In our previous study, fundamental mechanism of this dry coating process was revealed [18]: soft guest particles $\left(\mathrm{Na}_{2} \mathrm{SO}_{4}\right)$ are plastically deformed and coalesced with each other on a rigid host particle (NCM) due to high impact force derived from the dry impact-blending process. This results in formation of the coating layer of $\mathrm{Na}_{2} \mathrm{SO}_{4}$. Thus, it was considered that $80 \mathrm{~m} / \mathrm{s}$ of tip speed can provide sufficient impact force for plastic deformation and coalescence of $\mathrm{Na}_{2} \mathrm{SO}_{4}$ particles, while the impact force at $50 \mathrm{~m} / \mathrm{s}$ of tip speed was insufficient for the deformation and coalescence of $\mathrm{Na}_{2} \mathrm{SO}_{4}$ particles. At $100 \mathrm{~m} / \mathrm{s}$, further densification and discrete coating of $\mathrm{Na}_{2} \mathrm{SO}_{4}$ particles due to much higher impact force were observed.

Net weight fraction of $\mathrm{NCM}$ and $\mathrm{Na}_{2} \mathrm{SO}_{4}$ after dry coating at different tip speeds was shown in Table 1 (Run No. 1, 2, and 3). The net weight fraction of $\mathrm{Na}_{2} \mathrm{SO}_{4}$ after dry coating was lower than the initial weight fraction (30 wt $\%$ ) at every tip speed. This is due to adhesion of $\mathrm{Na}_{2} \mathrm{SO}_{4}$ particles onto the inner wall of the chamber and circulation pipe of the dry impact-blending device. At $50 \mathrm{~m} / \mathrm{s}$ of tip speed, the net weight fraction of $\mathrm{Na}_{2} \mathrm{SO}_{4}$ was significantly lower than the other higher tip speeds. This may be 
due to less sticking of $\mathrm{Na}_{2} \mathrm{SO}_{4}$ particles onto NCM particles under too lower impact force.

Fig. 3 b shows increase in electrical resistivity $\left(R_{\text {inc }}\right)$ defined by the Eq. (1) as a function of tip speed of rotor. The coated particles prepared at 80 and $100 \mathrm{~m} / \mathrm{s}$ showed remarkably higher $R_{\text {inc }}$ than those prepared at $50 \mathrm{~m} / \mathrm{s}$. When the solid-solid interfacial contacts between conductive NCM particles and non-conductive $\mathrm{Na}_{2} \mathrm{SO}_{4}$ particles are well formed in the pellet, $R_{\text {inc }}$ shows higher value. Thus, it was confirmed that the NCM particles were coated with $\mathrm{Na}_{2} \mathrm{SO}_{4}$ at 80 and $100 \mathrm{~m} / \mathrm{s}$ of the tip speed, while the NCM particles were not well coated at $50 \mathrm{~m} / \mathrm{s}$ of the tip speed. Fig. 3c shows size distributions of NCM particles after washing out $\mathrm{Na}_{2} \mathrm{SO}_{4}$ from the coated particles prepared at different tip speeds. Although a slight decrease in the particle size was found at the higher tip speed, change in the particle size distribution was subtle and not significant. Thus, NCM particles were not damaged at less than $100 \mathrm{~m} / \mathrm{s}$ of the tip speed within $300 \mathrm{~s}$ of the processing time.

In summary, we found that the tip speed higher than $80 \mathrm{~m} / \mathrm{s}$ can provide sufficient impact force for plastic deformation and coalescence of $\mathrm{Na}_{2} \mathrm{SO}_{4}$ particles, resulting in coated particles fully covered with the $\mathrm{Na}_{2} \mathrm{SO}_{4}$ particles.

\subsection{Effect of processing time}

Fig. 4a shows FESEM and EDX images of coated particles at various processing times (Run No. 4, 6, and 7 in Table 2). Both of manganese and sulfur were detected from same particle at each processing time. This indicates that $\mathrm{NCM}$ particles were covered with $\mathrm{Na}_{2} \mathrm{SO}_{4} \cdot$. With an increase in the processing time, surface morphology of coated particles exhibited a significant change from the discrete coating $(60 \mathrm{~s}$ and $600 \mathrm{~s})$ to the continuous coating $(1800 \mathrm{~s})$. This is due to much higher mechanical input energy at longer processing time, promoting plastic deformation and coalescence of $\mathrm{Na}_{2} \mathrm{SO}_{4}$ particles.

Table 1 (Run No. 3 to 7) shows the net weight fraction of $\mathrm{NCM}$ and $\mathrm{Na}_{2} \mathrm{SO}_{4}$ after the dry coating at different processing times. The net weight fraction of $\mathrm{Na}_{2} \mathrm{SO}_{4}$ was almost constant at $20 \mathrm{wt} \%$ regardless of the processing time. This indicates that amount of $\mathrm{Na}_{2} \mathrm{SO}_{4}$ adhered onto the inner wall of the chamber and circulation pipe immediately reached to an equilibrium within $60 \mathrm{~s}$. It is also considered that amount of $\mathrm{Na}_{2} \mathrm{SO}_{4}$ adhered onto NCM particles also reached to an equilibrium within 60 s, followed by densification, plastic deformation, and coalescence of $\mathrm{Na}_{2} \mathrm{SO}_{4}$ with an increase in the processing time.

Fig. $4 \mathrm{~b}$ shows increase in electrical resistivity $\left(R_{\text {inc }}\right)$ as a function of the processing time. It should be noted that coated particles prepared at $1800 \mathrm{~s}$ of the processing time showed remarkably higher

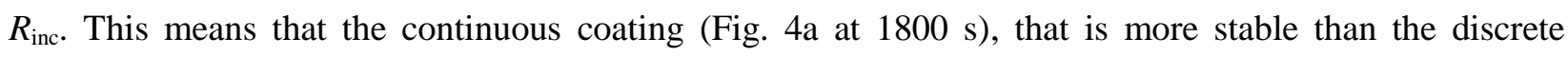


coating, can provide a more ideal structure in the compressed pellet: the solid-solid interfacial contacts between conductive $\mathrm{NCM}$ and non-conductive $\mathrm{Na}_{2} \mathrm{SO}_{4}$ can be well formed from coated particles covered with the continuous coating layer. Fig. 4c shows particle size distributions of NCM particles after washing out $\mathrm{Na}_{2} \mathrm{SO}_{4}$ from the coated particles. Within $600 \mathrm{~s}$ of the processing time reduction in the particle size from that of the original NCM particles was not significant, suggesting that breakage of the host particles did not occur at an early stage of the dry coating. This is due to the cushioning effect of the guest particles. At much longer processing time (1800 s), however, significant decrease in the particle size due to breakage of the NCM was found. This may be due to an increase in the impact force acting on the NCM particles, resulting from thinning of the coating layer at longer processing time. Moreover, this may be due to the fatigue breakage of NCM particles at longer processing time.

In summary, a longer processing time, i.e., higher mechanical input energy, leads to formation of the continuous coating layer of $\mathrm{Na}_{2} \mathrm{SO}_{4}$ particles, although a longer processing time can result in significant damage of the NCM particles. It was also revealed that the continuous coating is desirable surface morphology for formation of a more ideal structure in the compressed pellet.

\subsection{Effect of initial weight fraction of host and guest particles}

For composite electrodes of the ASS-LIBs, higher content of electrode particles and lower content of SEs are desired to achieve higher energy density [4]. Thus, effect of the initial weight fraction was investigated within lower weight fraction of $\mathrm{Na}_{2} \mathrm{SO}_{4}$ than $30 \mathrm{wt} \%$ as shown in Table 1 (Run No. 8 to 10). Fig. 5a shows FESEM and EDX images of coated particles at different initial weight fraction of NCM and $\mathrm{Na}_{2} \mathrm{SO}_{4}$ particles. Detection of both elements (manganese and sulfur) from same single particle indicates that $\mathrm{NCM}$ particles were covered with $\mathrm{Na}_{2} \underline{\mathrm{SO}}_{4} \underline{a}_{3}$ at each initial weight fraction. Even at relatively shorter processing time $(=300 \mathrm{~s})$, the continuous coating was formed at less than $20 \mathrm{wt} \%$ of $\mathrm{Na}_{2} \mathrm{SO}_{4}$, while the discrete coating was observed at $30 \mathrm{wt} \%$ of $\mathrm{Na}_{2} \mathrm{SO}_{4}$ (Fig. $3 \mathrm{a}$ at $100 \mathrm{~m} / \mathrm{s}$ of tip speed). This is due to higher mechanical input energy per unit mass of $\mathrm{Na}_{2} \mathrm{SO}_{4}$ at lower fraction of $\mathrm{Na}_{2} \mathrm{SO}_{4}$, promoting the plastic deformation and coalescence of $\mathrm{Na}_{2} \mathrm{SO}_{4}$ particles within shorter processing time.

Table 1 (Run No. 3, 8, 9 and 10) shows the net weight fraction of $\mathrm{NCM}$ and $\mathrm{Na}_{2} \mathrm{SO}_{4}$ after dry coating at different initial weight fraction. At initial weight fraction lower than $10 \mathrm{wt} \%$ of $\mathrm{Na}_{2} \mathrm{SO}_{4}(\mathrm{Run}$ No. 9 and 10), the net weight fraction was almost unchanged from the initial weight fraction. This indicates that at the lower initial fraction most of the $\mathrm{Na}_{2} \mathrm{SO}_{4}$ particles were firmly adhered onto the NCM particles and turned to the continuous coating without loss of $\mathrm{Na}_{2} \mathrm{SO}_{4}$ due to adhesion onto the wall of the 
dry coating device.

Fig. 5b shows increase in electrical resistivity $\left(R_{\text {inc }}\right)$ as a function of the initial weight fraction of $\mathrm{Na}_{2} \mathrm{SO}_{4} . R_{\text {inc }}$ at $20 \mathrm{wt} \%$ of the initial weight fraction showed higher than that at $30 \mathrm{wt} \%$ despite lower net weight fraction of $\mathrm{Na}_{2} \mathrm{SO}_{4}$. This confirms that the continuous coating is advantageous over the discrete coating for formation of the solid-solid interfacial contacts between $\mathrm{NCM}$ and $\mathrm{Na}_{2} \mathrm{SO}_{4}$ in the compressed pellet. At lower than $20 \mathrm{wt} \%, R_{\text {inc }}$ became smaller with a decrease in the initial weight fraction of $\mathrm{Na}_{2} \mathrm{SO}_{4}$. This may be due to thinner thickness of the coating layer, inducing formation of electrical conduction pass of conductive NCM particles in the compressed pellet. Fig. 5c shows size distributions of NCM particles after washing out $\mathrm{Na}_{2} \mathrm{SO}_{4}$ from the coated particles prepared at different initial weight fraction of $\mathrm{Na}_{2} \mathrm{SO}_{4}$. At less than $10 \mathrm{wt} \%$ of $\mathrm{Na}_{2} \mathrm{SO}_{4}$ significant breakage of $\mathrm{NCM}$ particles was observed due to less cushioning effect of $\mathrm{Na}_{2} \mathrm{SO}_{4}$, while no significant breakage of NCM particles was observed at 20 and 30 wt $\%$ of $\mathrm{Na}_{2} \mathrm{SO}_{4}$.

In summary, the continuous coating is able to be formed by decreasing the initial weight fraction of $\mathrm{Na}_{2} \mathrm{SO}_{4}$ particles, i.e., by increasing the mechanical input energy per unit mass of $\mathrm{Na}_{2} \mathrm{SO}_{4}$ particles. The initial weight fraction can be maintained after the dry coating at less than $10 \mathrm{wt} \%$ of the initial weight fraction of $\mathrm{Na}_{2} \mathrm{SO}_{4}$.

\subsection{Mechanism of dry coating in this study}

Through the above-mentioned parametric investigations, mechanism of the dry coating process in this study was proposed as illustrated in Fig. 6. At an initial state (Fig. 6a), host particles (NCM) are partially covered with guest particles $\left(\mathrm{Na}_{2} \mathrm{SO}_{4}\right)$ by the mortar-and-pestle pre-mixing. Under insufficient impact force, i.e., too low tip speed of rotor, host particles are not fully coated with guest particles but partially coated (Fig. 6b). Under excess impact force, it is expected that host particles can be immediately broken (Fig. 6g). Under a sufficient impact force, densification of guest particles on the surface of host particles occurs, resulting in the discrete coating (Fig. 6c). With an increase in the processing time, i.e., increase in the mechanical input energy, plastic deformation and coalescence of guest particles are promoted (Fig. 6d), resulting in the continuous coating (Fig. 6e). This morphological change is more pronounced at less initial weight fraction of guest particles due to higher mechanical input energy per unit mass of guest particles. With further increase in the mechanical input energy, breakage of the host particles is induced (Fig. 6f). It is considered that the dry coating mechanism shown in Fig. 6 can be applied to other type of powder handling equipment in which mechanical forces are imparted to the particles, while 
the powder handling equipment which is able to achieve the continuous coating (Fig. 6 (e), suitable coating state for the ASS-LIBs) is considered to be limited.

\subsection{Determination of optimal processing condition}

Based on the above-mentioned mechanism, the optimal processing conditions were determined. To achieve better performance of the ASS-LIBs, following particle design is required in the dry coated particles: (1) no breakage of host (electrode) particles; (2) the continuous coating; (3) less fraction of guest (SE) particles. We proposed optimal processing conditions where the above-requirements can be fulfilled. The proposed optimal processing conditions were shown at Run No. 11 in Table 1. We preliminarily examined reduction in the initial weight fraction of guest particles and have found that the lower limit is $10 \mathrm{wt} \%$. At less than $10 \mathrm{wt} \%$ of $\mathrm{Na}_{2} \mathrm{SO}_{4}$, breakage of $\mathrm{NCM}$ was inevitable. To verify the proposed optimal conditions, the dry coated particles was prepared and characterized. Fig. 7a and b shows FESEM images of coated particles prepared at the proposed optimal conditions. NCM particles were fully covered with the continuous layer of $\mathrm{Na}_{2} \mathrm{SO}_{4}$. Thickness of the coating layer was around $0.15 \mu \mathrm{m}$. The initial weight fraction of $\mathrm{NCM}$ and $\mathrm{Na}_{2} \mathrm{SO}_{4}$ was almost maintained even after the dry coating (Run No. 11 in Table 1). Fig. 7c shows size distributions of NCM particles after washing out $\mathrm{Na}_{2} \mathrm{SO}_{4}$ from the coated particles. No significant breakage of NCM was found even at relatively less fraction of guest particles. Fig. 7d shows FESEM images of NCM particle after washing out $\mathrm{Na}_{2} \mathrm{SO}_{4}$ from the coated particles. Surface morphology was unchanged from the pristine NCM (Fig. 2b). These results confirmed that NCM particles were able to be coated with less fraction of $\mathrm{Na}_{2} \mathrm{SO}_{4}(10 \mathrm{wt} \%)$ without breakage and attrition of the NCM particles. Fig. 7e and f shows FESEM images of cross-section of compressed pellet prepared from the coated particles. In the compressed pellet, $\mathrm{NCM}$ particles (light gray region) were well dispersed in $\mathrm{Na}_{2} \mathrm{SO}_{4}$ matrix (dark gray region) without agglomeration, and the solid-solid interfacial contact between electrode particles ( $\mathrm{NCM})$ and model material of SEs $\left(\mathrm{Na}_{2} \mathrm{SO}_{4}\right)$ were well formed.

$\underline{\text { In this study, the guest particles with a bimodal particle size distribution were used. We consider }}$ that the bimodal size distribution of the guest particles would not affect the optimal processing conditions. One of the concerns raised by the bimodal size distribution is segregation of larger guest particles from host particles. This can result in significant variation of the net weight fraction of the host and guest particles after coating from the initial weight fraction. However, the result in this study showed that the initial weight fraction of host and guest was almost maintained (Run No 11 in Table 11). This means that

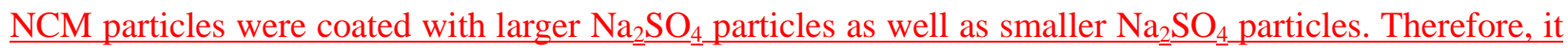


is considered that the bimodal size distribution of the guest particles used in this study would not affect the optimal conditions.

In most of the previous studies regarding the ASS-LIBs using sulfide SEs, weight fractions of SEs in the composite electrodes were higher than $30 \mathrm{wt} \%$ [4] to ensure ionic conducting pathways. Only Sakuda et al. [16] successfully reported coating of electrode particles with much less fraction of SE (= 10 $\mathrm{wt} \%$ ). However, they used a pulsed laser deposition (PLD) technique, which is costly and far from being a practical use in industrial sectors, while the dry coating process is much more practical. Thus, the dry coating process that can coat electrode particles with much less amount of SEs without damage of the electrode particles is very promising to produce composite particles and electrodes for the ASS-LIBs.

\section{Conclusions}

A parametric study of the dry coating process, in which electrode particles were coated with model material of sulfide solid electrolytes, was conducted. $\mathrm{LiNi}_{1 / 3} \mathrm{Co}_{1 / 3} \mathrm{Mn}_{1 / 3} \mathrm{O}_{2}(\mathrm{NCM})$ was used as a host particle. Sodium sulfate $\left(\mathrm{Na}_{2} \mathrm{SO}_{4}\right)$ was selected as a model material of sulfide solid electrolytes and used as a guest particle. A dry impact-blending process known as "Hybridizer" was used. Effects of critical process parameters including tip speed of rotor, processing time, and initial weight fraction of host and guest particles were investigated.

Under too low tip speed of rotor NCM particles were not fully covered with $\mathrm{Na}_{2} \mathrm{SO}_{4}$ due to insufficient impact force, while under a sufficient tip speed NCM particles were fully covered and the discrete coating of $\mathrm{Na}_{2} \mathrm{SO}_{4}$ particles on the surface of NCM particles were observed. With an increase in the processing time, plastic deformation and coalescence of $\mathrm{Na}_{2} \mathrm{SO}_{4}$ particles were promoted, resulting in the continuous coating. This morphological change was more pronounced at less initial weight fraction of $\mathrm{Na}_{2} \mathrm{SO}_{4}$ due to higher mechanical input energy per unit mass of $\mathrm{Na}_{2} \mathrm{SO}_{4}$. With further increase in the mechanical input energy, breakage of the NCM particles was caused. The continuous coating, that is more stable than the discrete coating, showed a great advantage over the discrete coating for formation of the $\underline{\mathrm{NCM}-\mathrm{Na}_{2}} \underline{\mathrm{SO}}_{4}$ interfacial contacts in the compressed pellet. Based on the parametric investigations, the optimal processing conditions were finally determined. At the determined optimal conditions, NCM particles were successfully coated by the continuous layer of much less amount of $\mathrm{Na}_{2} \mathrm{SO}_{4}$ without breakage of NCM particles. 


\section{Acknowledgements}

This work was financially supported by Japan Science and Technology Agency (JST), Advanced Low Carbon Technology Research and Development Program-Specially Promoted Research for Innovative Next Generation Batteries (ALCA-SPRING). The authors would like to acknowledge Profs. M. Tatsumisago and A. Hayashi (Osaka Prefecture University) for FESEM and EDX observations.

\section{References}

[1] B. Dunn, H. Kamath, and J. M. Tarascon, Electrical energy storage for the grid: a battery of choices, Science 334 (2011) 928-935.

[2] B. Scrosati, J. Garche, Lithium batteries: status, prospects and future, J. Power Sources 195 (2010) 2419-2430.

[3] M. Tatsumisago, A. Hayashi, Superionic glasses and glass-ceramics in $\mathrm{Li}_{2} \mathrm{~S}-\mathrm{P}_{2} \mathrm{~S}_{5}$ system for all-solid-state lithium secondary batteries, Solid State Ionics 225 (2012) 342-345.

[4] Y. S. Jung, D. Y. Oh, Y. J. Nam, K. H. Park, Issues and challenges for bulk-type all-solid-state rechargeable lithium batteries using sulfide solid electrolytes, Isr. J. Chem. 55 (2015) 472-485.

[5] K. Takada, Progress and prospective of solid-state lithium batteries, Acta Mater. 61 (2013) 759-770.

[6] A. Pradel, M. Ribes, Electrical properties of lithium conductive silicon sulfide glasses prepared by twin roller quenching, Solid State Ionics 18-19 (1986) 351-355.

[7] R. Mercier, J. P. Malugani, B. Fahys, G. Robert, Superionic conduction in $\mathrm{Li}_{2} \mathrm{~S}_{-} \mathrm{P}_{2} \mathrm{~S}_{5}$-LiI-glasses, Solid State Ionics 5 (1981) 663-666.

[8] A. Hayashi, S. Hama, T. Minami, M. Tatsumisago, Formation of superionic crystals from mechanically milled $\mathrm{Li}_{2} \mathrm{~S}-\mathrm{P}_{2} \mathrm{~S}_{5}$ glasses, Electrochem. Commun. 5 (2003) 111-114.

[9] R. Kanno, M. Murayama, Lithium ionic conductor thio-LISICON: the $\mathrm{Li}_{2} \mathrm{~S}-\mathrm{GeS}_{2}-\mathrm{P}_{2} \mathrm{~S}_{5}$ system, J. Electrochem. Soc. 148 (2001) A742-A746.

[10] N. Kamaya, K. Homma, Y. Yamakawa, M. Horayama, R. Kanno, M. Yonemura, T. Kamiyama, Y. Kato, S. Hama, K. Kawamoto, A. Mitsui, A lithium superionic conductor, Nat. Mater. 10 (2011) 682-686.

[11] A. Sakuda, T. Takeuchi, H. Kobayashi, Electrode morphology in all-solid-state lithium secondary batteries consisting of $\mathrm{LiNi}_{1 / 3} \mathrm{Co}_{1 / 3} \mathrm{Mn}_{1 / 3} \mathrm{O}_{2}$ and $\mathrm{Li}_{2} \mathrm{~S}-\mathrm{P}_{2} \mathrm{~S}_{5}$ solid electrolytes, Solid State Ionics 285 (2016) 112-117.

[12] J. Kim, M. Eom, S. Noh, D. Shin, Effect of mixing method on the properties of composite cathodes for all-solid-state lithium batteries using $\mathrm{Li}_{2} \mathrm{~S}-\mathrm{P}_{2} \mathrm{~S}_{5}$ solid electrolytes. J. Power Sources 244 (2013) 
476-481.

[13] F. Mizuno, A. Hayashi, K. Tadanaga, M. Tatsumisago, Effect of conductive additives in composite positive electrodes on charge-discharge behaviors of all-solid-state lithium secondary batteries, J. Electrochem. Soc., 152 (2005) A1499-A1503.

[14] M. Nagao, A. Hayashi, M. Tatsumisago, High-capacity $\mathrm{Li}_{2} \mathrm{~S}$-nanocarbon composite electrode for all-solid-state rechargeable lithium batteries, J. Mater. Chem. 22 (2012) 10015-10020.

[15] A. Sakuda, A. Hayashi, T. Ohtomo, S. Hama, M. Tatsumisago, All-solid-state lithium secondary batteries using $\mathrm{LiCoO}_{2}$ particles with pulsed laser deposition coatings of $\mathrm{Li}_{2} \mathrm{~S}-\mathrm{P}_{2} \mathrm{~S}_{5}$ solid electrolytes, J. Power Sources 196 (2011) 6735-6741.

[16] A. Sakuda, A. Hayashi, M. Tatsumisago, Sulfide solid electrolyte with favorable mechanical property for all-solid-state lithium battery, Sci. Rep. 3 (2013) 2261.

[17] H. Kitaura, A. Hayashi, T. Ohtomo, S. Hama, M. Tatsumisago, Fabrication of electrode-electrolyte interfaces in all-solid-state rechargeable lithium batteries by using a supercooled liquid state of the glassy electrolytes, J. Mater. Chem. 21 (2011) 118-124.

[18] T. Kawaguchi, H. Nakamura, S. Watano, Dry coating of electrode particle with model particle of sulfide solid electrolytes for all-solid-state secondary battery, Powder Technol., in press. 


\section{Captions of Figures and Table}

Fig. 1. Schematic of dry impact-blending device (Hybridizer).

Fig. 2. (a) Volume based particle size distributions of $\mathrm{LiNi}_{1 / 3} \mathrm{Co}_{1 / 3} \mathrm{Mn}_{1 / 3} \mathrm{O}_{2}(\mathrm{NCM})$ and $\mathrm{Na}_{2} \mathrm{SO}_{4}$. FESEM images of (b) $\mathrm{NCM}$ and (c) $\mathrm{Na}_{2} \mathrm{SO}_{4}$

Fig. 3. Effects of tip speed of rotor (Run No. 1,2 and 3). (a) FESEM and EDX images of coated particles. (b) Increase in electrical resistivity as a function of tip speed of rotor. (c) Volume based size distributions of $\mathrm{NCM}$ particles after washing out $\mathrm{Na}_{2} \mathrm{SO}_{4}$ from coated particles.

Fig. 4. Effects of processing time (Run No. 3, 4, 5,6 and 7). (a) FESEM and EDX images of coated particles. (b) Increase in electrical resistivity as a function of processing time. (c) Volume based particle size distributions of $\mathrm{NCM}$ particles after washing out $\mathrm{Na}_{2} \mathrm{SO}_{4}$ from coated particles.

Fig. 5. Effects of initial weight fraction of $\mathrm{NCM}$ and $\mathrm{Na}_{2} \mathrm{SO}_{4}$ (Run No. 3, 8, 9 and 10). (a) FESEM and EDX images of coated particles. (b) Increase in electrical resistivity as a function of initial weight fraction of $\mathrm{Na}_{2} \mathrm{SO}_{4}$. (c) Volume based particle size distributions of $\mathrm{NCM}$ particles after washing out $\mathrm{Na}_{2} \mathrm{SO}_{4}$ from coated particles prepared at different initial weight fraction of $\mathrm{Na}_{2} \mathrm{SO}_{4}$.

Fig. 6. Mechanism of dry coating in this study.

Fig. 7. Coated particles prepared at optimal processing conditions (Run No. 11). FESEM images of (a) coated particles and (b) cross-section of single coated particles. Light gray and dark gray region corresponds to NCM and $\mathrm{Na}_{2} \mathrm{SO}_{4}$, respectively. (b) Volume based particle size distribution and (c) FESEM images of NCM particles after washing out $\mathrm{Na}_{2} \mathrm{SO}_{4}$ from coated particles. FESEM images of cross-section of compressed pellet prepared from coated particles at (e) lower magnification (x 2,000) and (b) higher magnification (x 5,000). Light gray and dark gray region corresponds to $\mathrm{NCM}$ and $\mathrm{Na}_{2} \mathrm{SO}_{4}$, respectively.

Table 1 Experimental conditions and net weight fraction of $\mathrm{NCM}$ and $\mathrm{Na}_{2} \mathrm{SO}_{4}$ after dry coating 


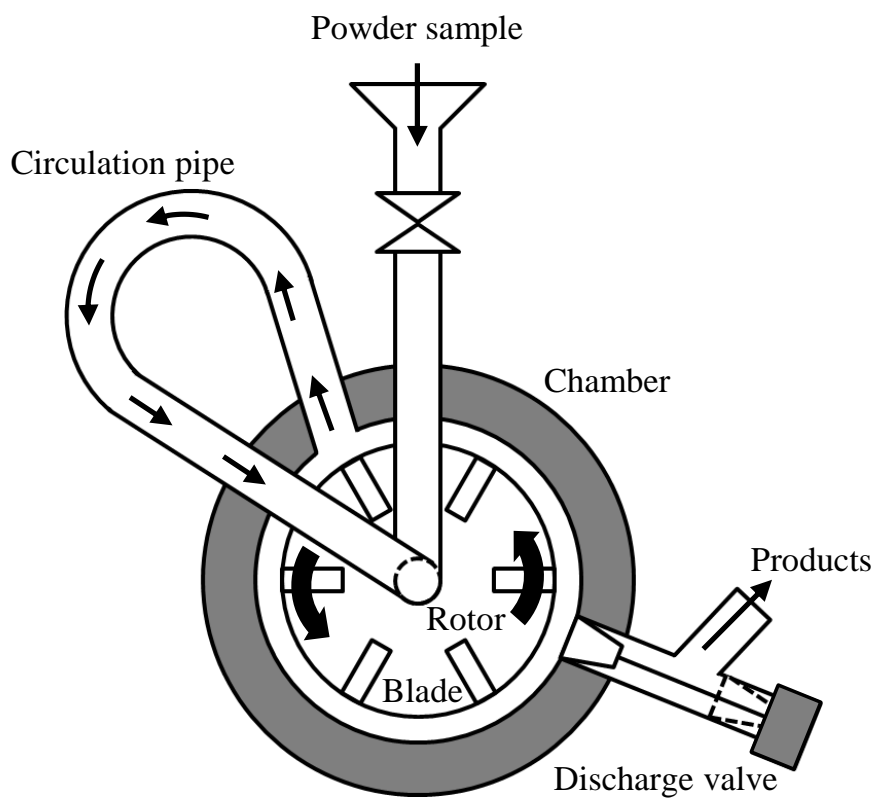

Fig. 1. Schematic of dry impact-blending device (Hybridizer). 

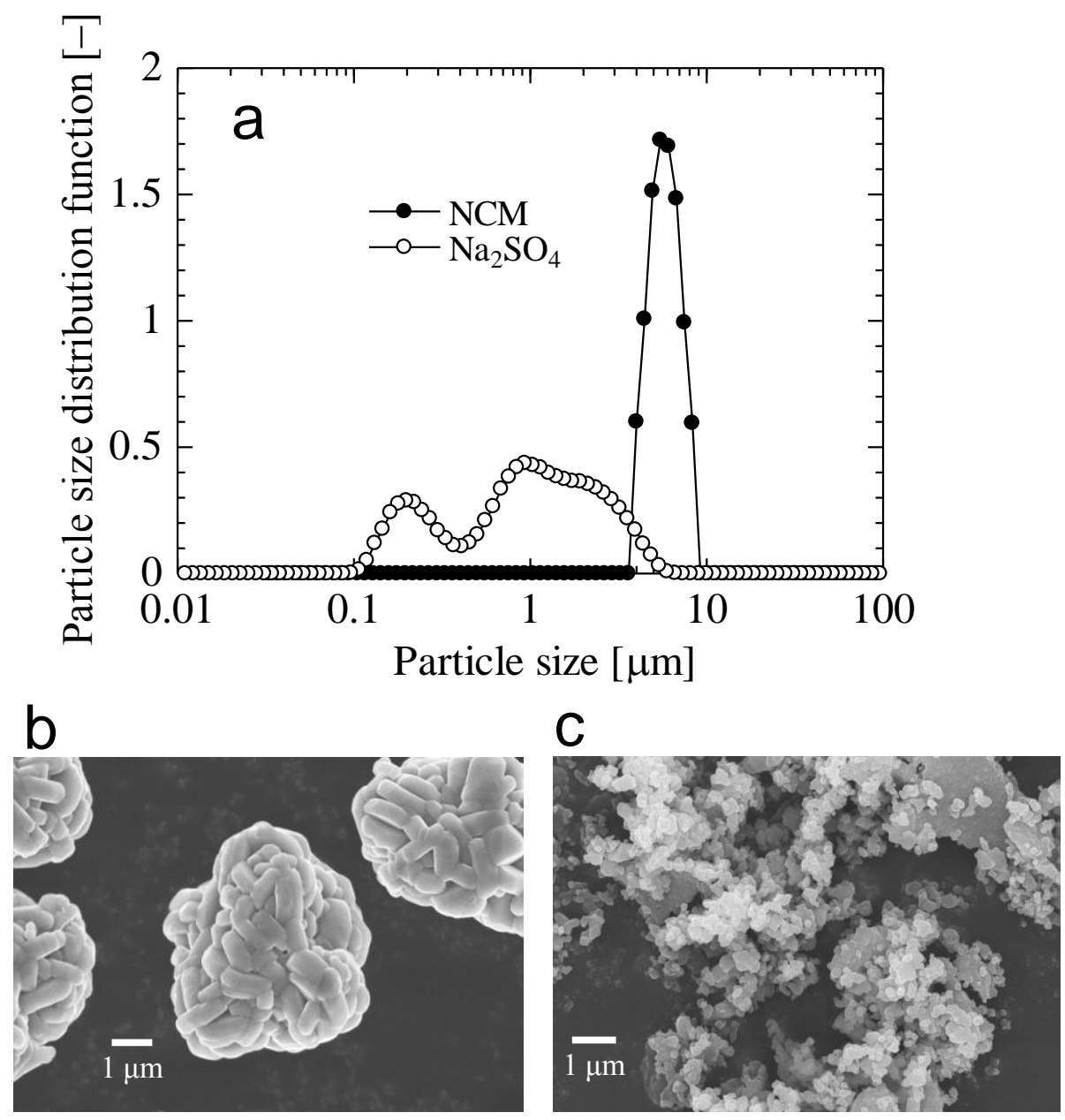

Fig. 2. (a) Volume based particle size distributions of $\mathrm{LiNi}_{1 / 3} \mathrm{Co}_{1 / 3} \mathrm{Mn}_{1 / 3} \mathrm{O}_{2}(\mathrm{NCM})$ and $\mathrm{Na}_{2} \mathrm{SO}_{4}$. FESEM images of (b) NCM and (c) $\mathrm{Na}_{2} \mathrm{SO}_{4}$ 


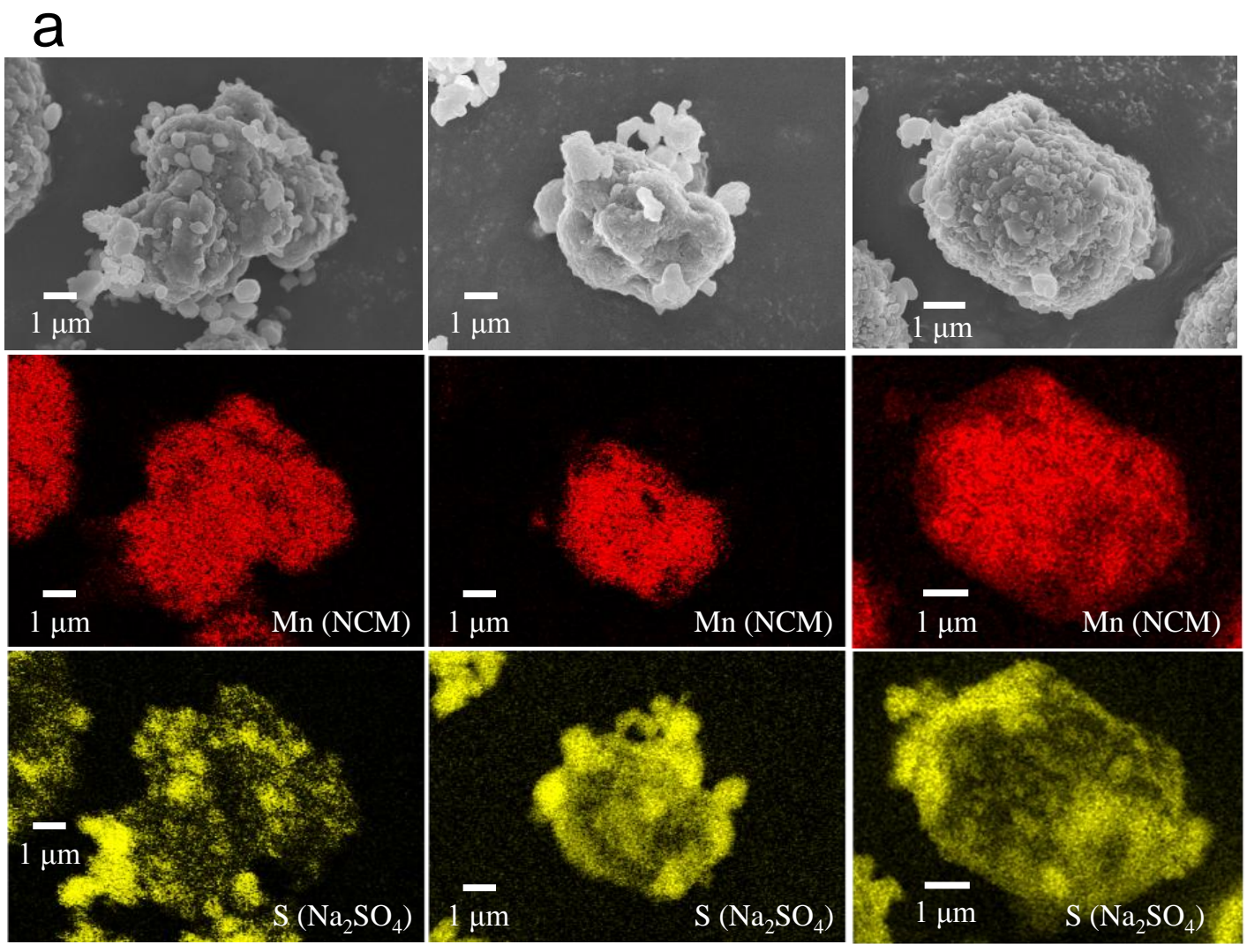

Tip speed of rotor $=50 \mathrm{~m} / \mathrm{s} \quad$ Tip speed of rotor $=80 \mathrm{~m} / \mathrm{s} \quad$ Tip speed of rotor $=100 \mathrm{~m} / \mathrm{s}$
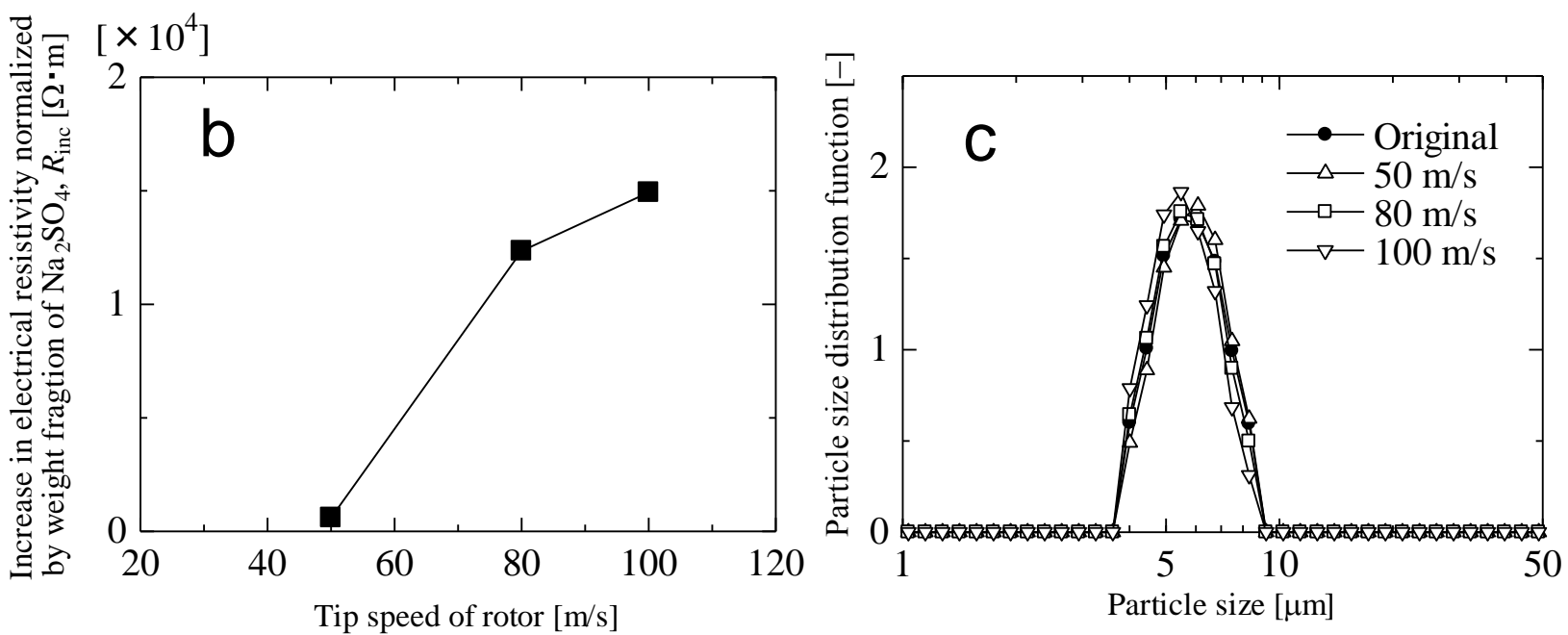

Fig. 3. Effects of tip speed of rotor (Run No. 1,2 and 3). (a) FESEM and EDX images of coated particles. (b) Increase in electrical resistivity as a function of tip speed of rotor. (c) Volume based size distributions of NCM particles after washing out $\mathrm{Na}_{2} \mathrm{SO}_{4}$ from coated particles. 


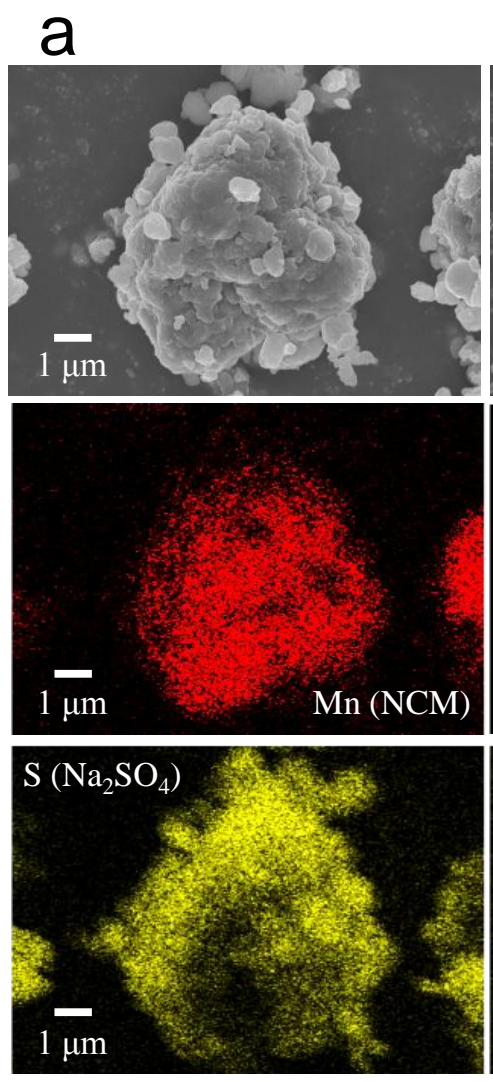

Processing time $=60 \mathrm{~s}$
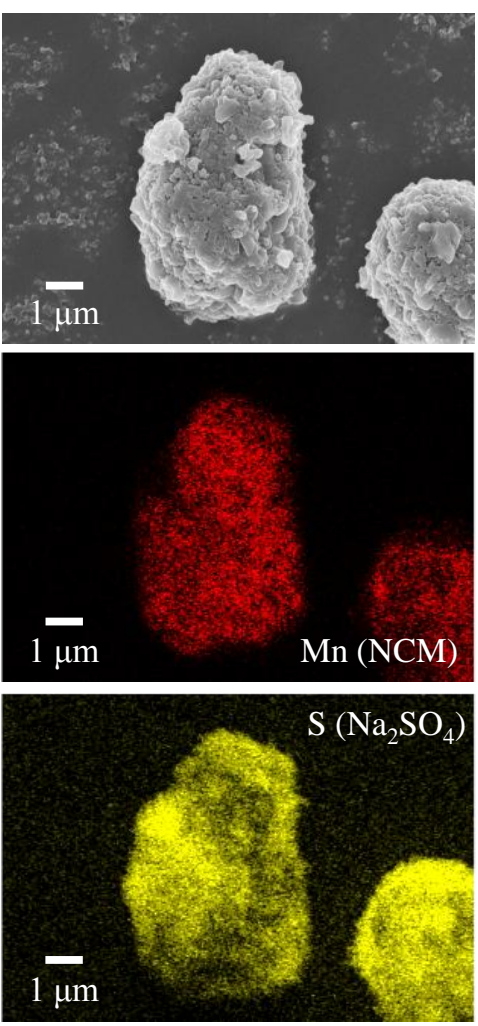

Processing time $=600 \mathrm{~s}$
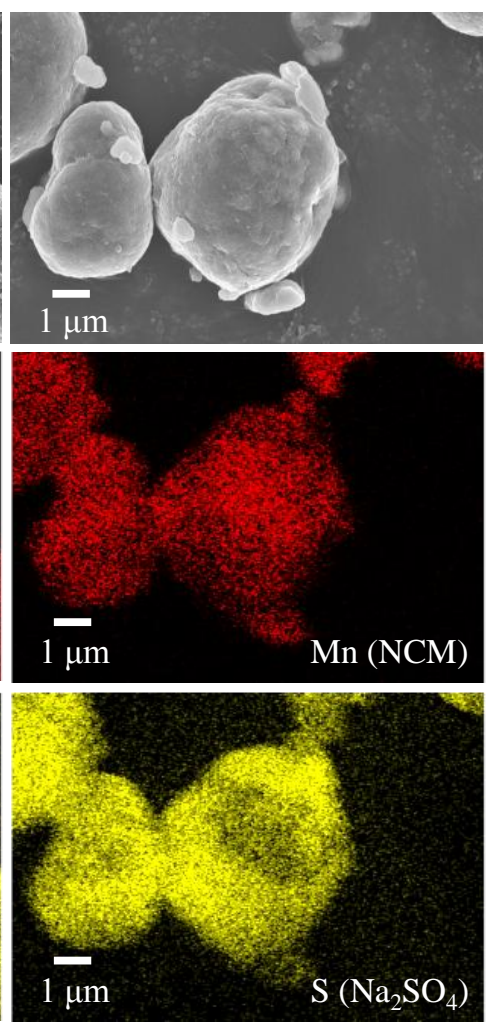

Processing time $=1800 \mathrm{~s}$

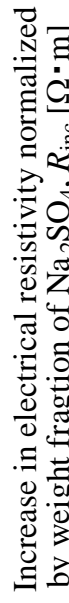

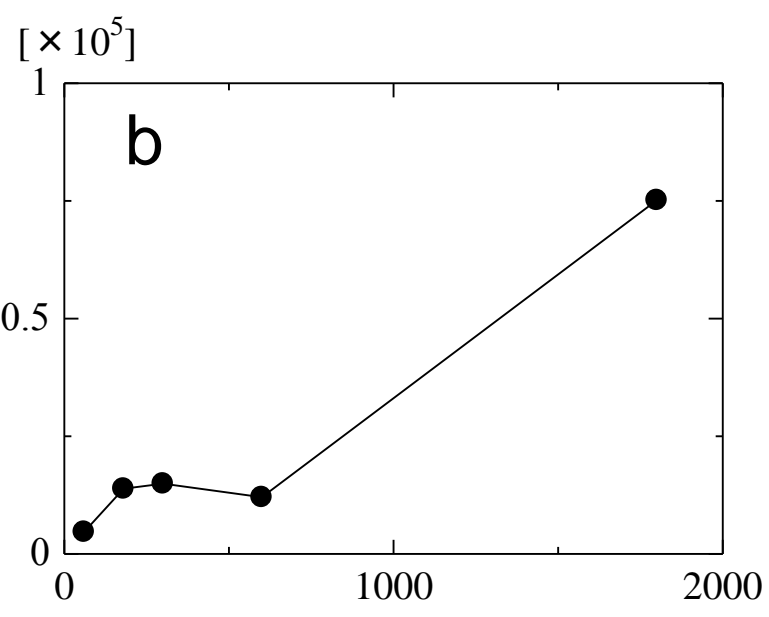

Processing time [s]

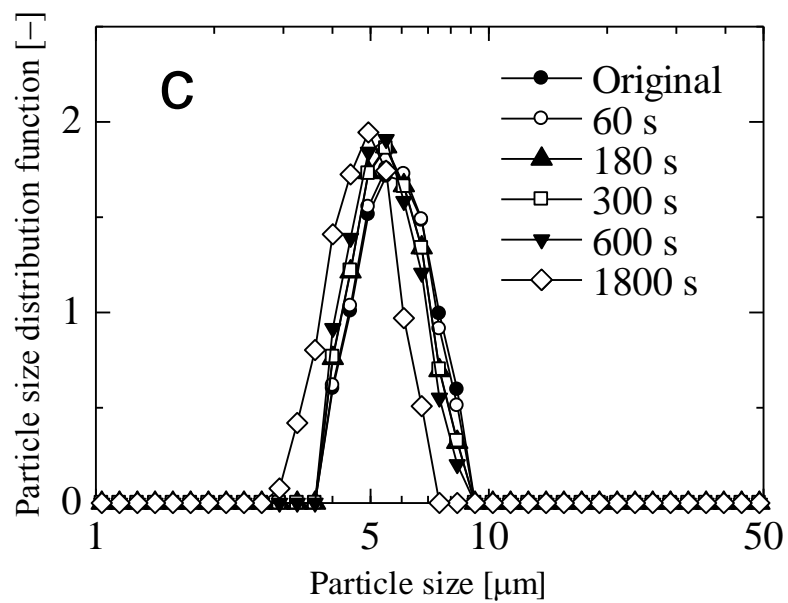

Particle size $[\mu \mathrm{m}]$

Fig. 4. Effects of processing time (Run No. 3, 4, 5, 6 and 7).. (a) FESEM and EDX images of coated particles. (b) Increase in electrical resistivity as a function of processing time. (c) Volume based particle size distributions of NCM particles after washing out $\mathrm{Na}_{2} \mathrm{SO}_{4}$ from coated particles. 
a
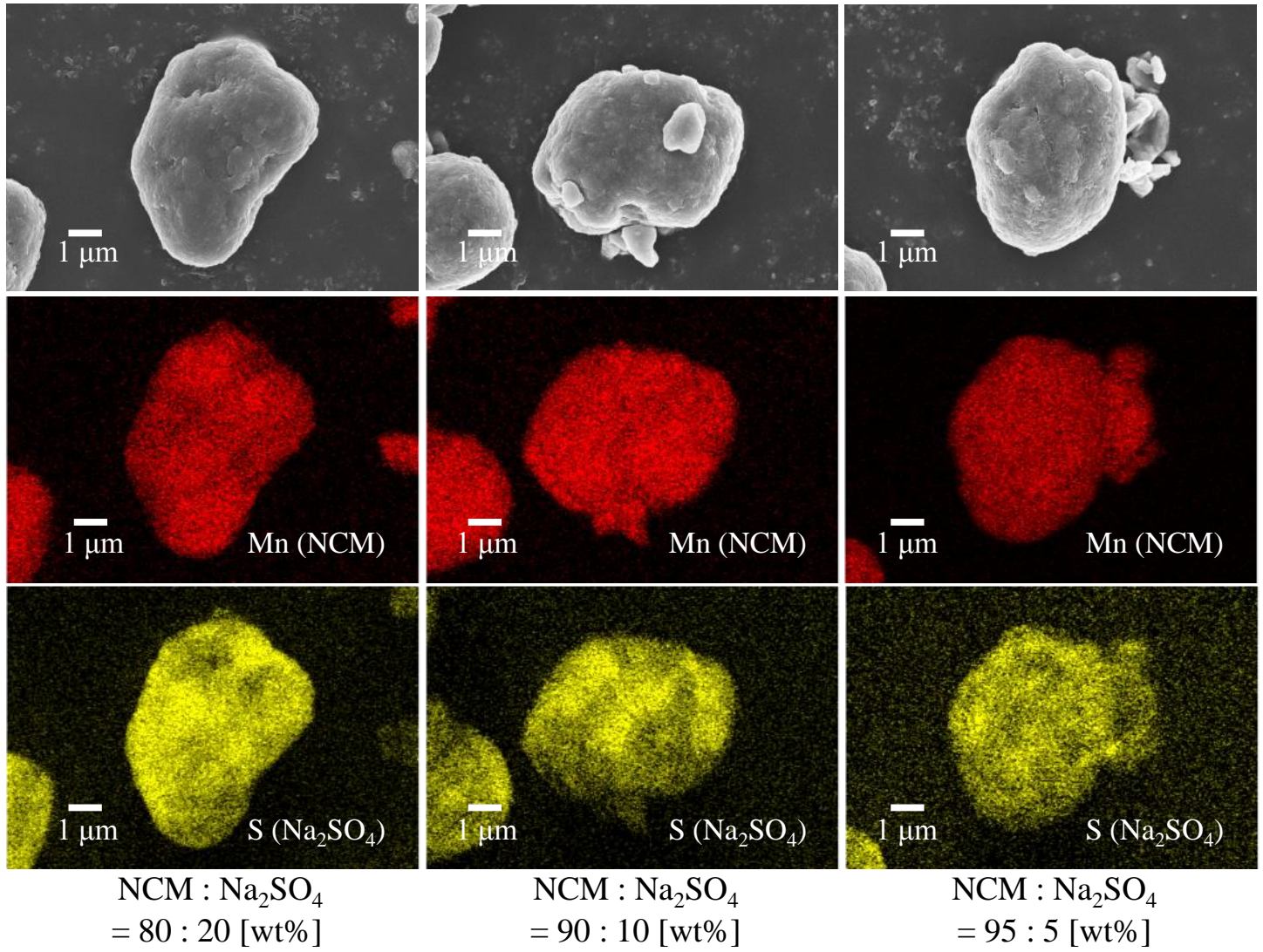

$\mathrm{NCM}: \mathrm{Na}_{2} \mathrm{SO}_{4}$ $=90: 10[\mathrm{wt} \%]$ $=95: 5[\mathrm{wt} \%]$
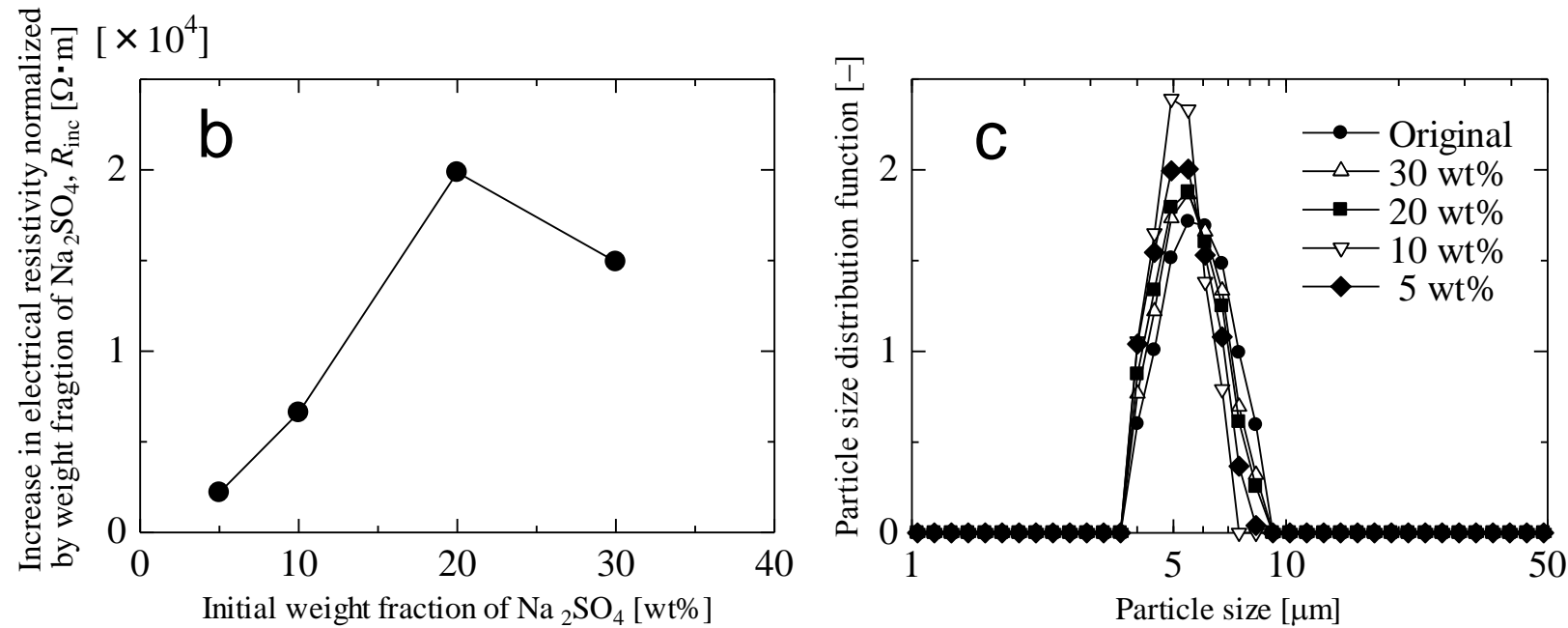

Fig. 5. Effects of initial weight fraction of $\mathrm{NCM}$ and $\mathrm{Na}_{2} \mathrm{SO}_{4}$ (Run No. 3, 8, 9 and 10). (a) FESEM and EDX images of coated particles. (b) Increase in electrical resistivity as a function of initial weight fraction of $\mathrm{Na}_{2} \mathrm{SO}_{4}$. (c) Volume based particle size distributions of NCM particles after washing out $\mathrm{Na}_{2} \mathrm{SO}_{4}$ from coated particles prepared at different initial weight fraction of $\mathrm{Na}_{2} \mathrm{SO}_{4}$. 

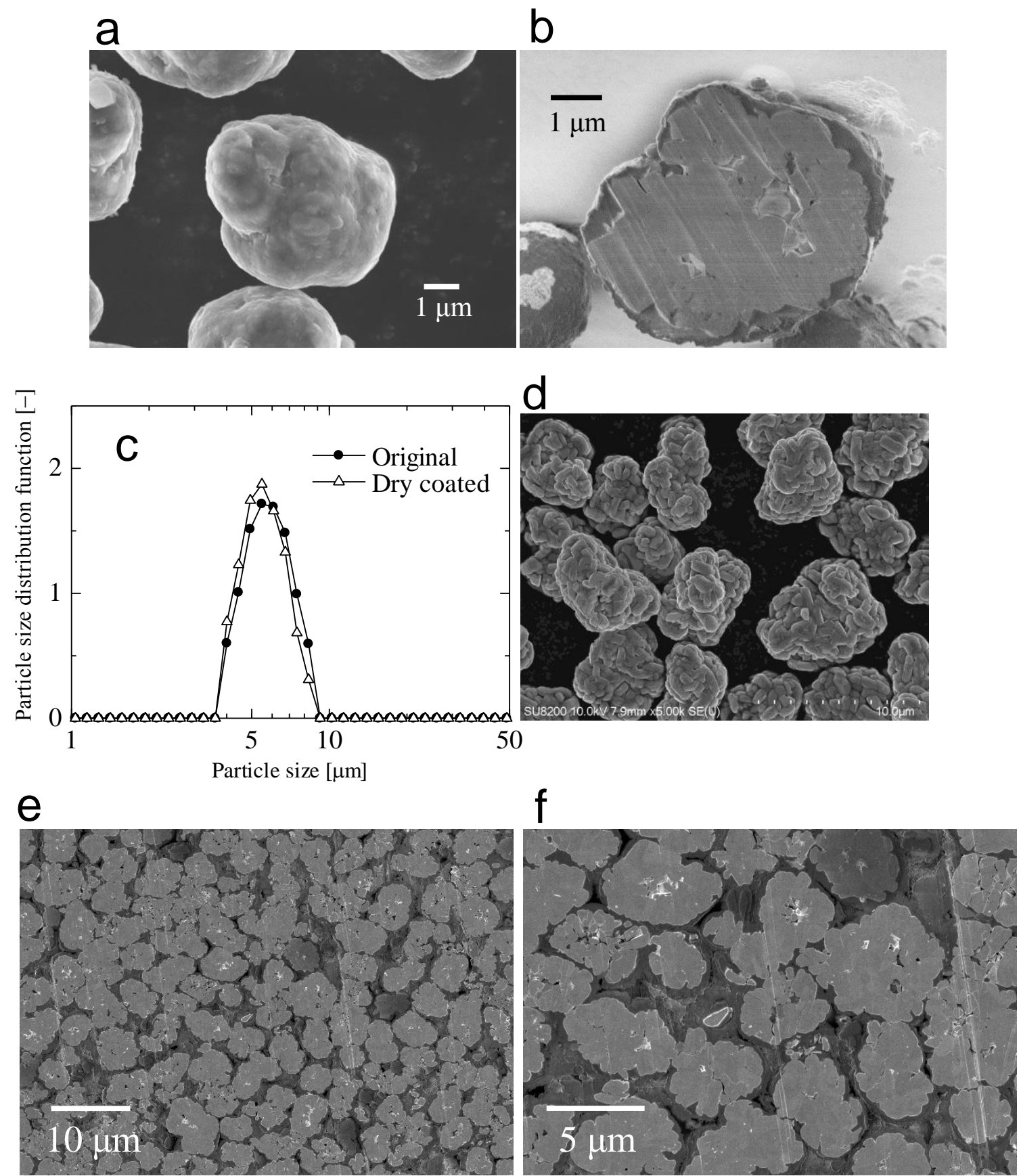

Fig. 7. Coated particles prepared at optimal processing conditions (Run No. 11). FESEM images of (a) coated particles and (b) cross-section of single coated particles. Light gray and dark gray region corresponds to NCM and $\mathrm{Na}_{2} \mathrm{SO}_{4}$, respectively. (b) Volume based particle size distribution and (c) FESEM images of NCM particles after washing out $\mathrm{Na}_{2} \mathrm{SO}_{4}$ from coated particles. FESEM images of cross-section of compressed pellet prepared from coated particles at (e) lower magnification (x 2,000) and (b) higher magnification (x 5,000). Light gray and dark gray region corresponds to $\mathrm{NCM}$ and $\mathrm{Na}_{2} \mathrm{SO}_{4}$, respectively. 
Table 1 Experimental conditions and net weight fraction of $\mathrm{NCM}$ and $\mathrm{Na}_{2} \mathrm{SO}_{4}$ after dry coating

\begin{tabular}{|c|c|c|c|c|}
\hline Run No. & $\begin{array}{l}\text { Tip speed of } \\
\text { rotor }[\mathrm{m} / \mathrm{s}]\end{array}$ & $\begin{array}{l}\text { Processing } \\
\text { time }[\mathrm{s}]\end{array}$ & $\begin{array}{l}\text { Initial weight fraction of } \\
\left.\mathrm{NCM}: \mathrm{Na}_{2} \mathrm{SO}_{4} \text { [wt } \%\right]\end{array}$ & $\begin{array}{c}\text { Net weight fraction of } \\
\mathrm{NCM}: \mathrm{Na}_{2} \mathrm{SO}_{4} \text { after dry coating [wt\%] }\end{array}$ \\
\hline 1 & 50 & 300 & $70: 30$ & $87.3: 12.7$ \\
\hline 2 & 80 & 300 & $70: 30$ & $78.5: 21.5$ \\
\hline 3 & 100 & 300 & $70: 30$ & $79.8: 20.2$ \\
\hline 4 & 100 & 60 & $70: 30$ & $78.9: 21.1$ \\
\hline 5 & 100 & 180 & $70: 30$ & $76.3: 23.7$ \\
\hline 6 & 100 & 600 & $70: 30$ & $79.1: 20.9$ \\
\hline 7 & 100 & 1800 & $70: 30$ & $80.5: 19.5$ \\
\hline 8 & 100 & 300 & $80: 20$ & $84.5: 15.5$ \\
\hline 9 & 100 & 300 & $90: 10$ & $90.8: 9.2$ \\
\hline 10 & 100 & 300 & $95: 5$ & $95.2: 4.8$ \\
\hline 11 & 80 & 300 & $90: 10$ & $90.2 \pm 0.5: 9.8 \pm 0.5^{*}$ \\
\hline
\end{tabular}


Initial weight fraction of guest particles

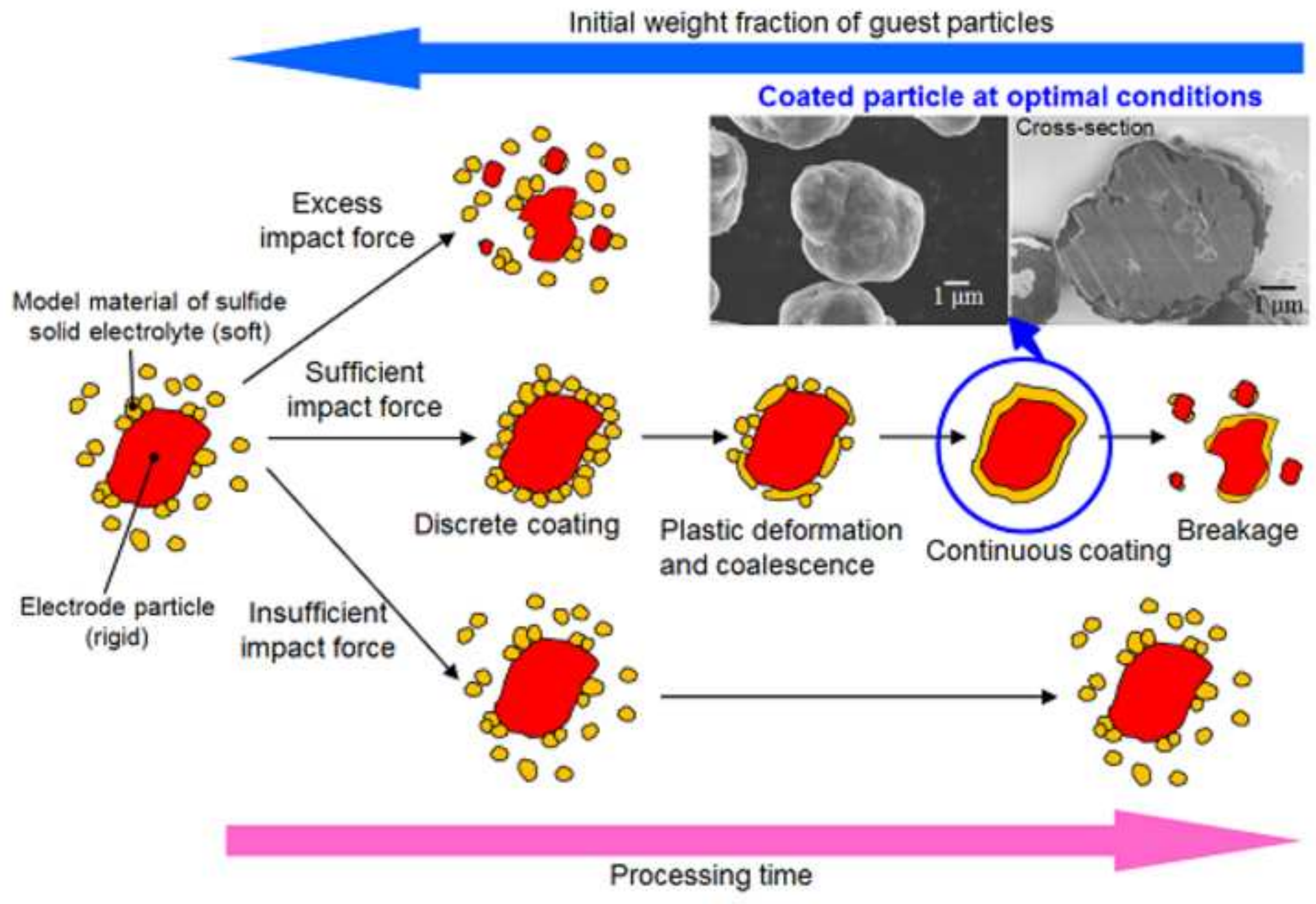

